\title{
Monomethyl Auristatin E
}

National Cancer Institute

\section{Source}

National Cancer Institute. Monomethyl Auristatin E. NCI Thesaurus. Code C122637.

A dolastatin-10 peptide derivative with potent antimitotic activity and potential antineoplastic activity as part of an antibody-drug conjug ate (ADC). Monomethyl auristatin $\mathrm{E}$ (MMAE) binds to tubulin, blocks tubulin polymerization, and inhibits microtubule formation, which results in both disruption of mitotic spindle assembly and arrest of tumor cells in the M phase of the cell cycle. To minimize toxicity and maximize efficacy, MMAE is conjugated, via a cleavable peptide linker, to a monoclonal antibody that specifically targets a patient's tumor. The linker is stable in the extracellular milieu but is readily cleaved to release MMAE following binding and internalization of the ADC by the target cells. 